\title{
Synthesis and capping of magnetic iron nanoparticles for biotechnological application.
}

\author{
Carolina N. Scachetti ${ }^{\star}$, Gabriela G. Souzedo, Stephanie F. F. Silva, Ljubica Tasic.
}

\begin{abstract}
Frequently, nanoparticles take part in biological and medicinal researches, once their small sizes are similar with ones of biological structures and/or molecules. This project aimed the synthesis and capping of magnetic iron nanoparticles for a biotechnological application using yeast invertase immobilization. Mesurements of zeta potential and DLS indicated that the capping was successfully achieved and the imobbilization of the invertase was confirmed by enzyme activity tests.
\end{abstract}

Key words: Magnetic iron nanoparticles, invertase, biotechnology.

\section{Introduction}

Nanoparticle-based technology is a growing field of research in the medical and biologal spheres, principally due to the nanometric size of the particles involved, which might be compared with the components of a cell, such as proteins (typical sizes of $5 \mathrm{~nm}$ ). Besides, some of the properties of nanomaterials, for instance, the optical or magnetic ones, are often explored with success in biological applications.

However, the nanoparticles sizes are not the criteria to apply them as biological tags. Their surfaces should be covered with a compound, which is biocompatible with the biological target, as a coat or a layer that will act as an interface for what is intended. ${ }^{1}$ In addition, the stabilization of the colloidal dispersion of the nanoparticles and, occasionally, protection against reactive conditions is also to be add-to this overlay.

The objective of this project is the synthesis of magnetic iron nanoparticles, their capping with tetraethoxysilane (TEOS), (3-aminopropyl) triethoxysilane (APTES), carboxymethyl cellulose (CMC) and glucosamine hydrochloride and, finally, the immobilization of the invertase enzyme from biological yeast for biotechnological applications.

\section{Results and Discussion}

The synthesis of the magnetic iron nanoparticles (FeNP) was made by the co-precipitation method, as shown in Reaction $1 .^{2}$

(1) $\mathrm{Fe}^{2+}+2 \mathrm{Fe}^{3+}=\mathrm{Fe}_{3} \mathrm{O}_{4}+4 \mathrm{H}_{2} \mathrm{O}$

Since these nanoparticles are sensitive to oxygen, both in solution and in the reactional atmosphere, their syntheses and manipulation until the capping step were performed under inert atmosphere. . $^{3,4}$

The overlay of the FeNP was made following the method proposed in the literature ${ }^{5}$ for all the compounds already mentioned.

Measurements of the dynamic light scattering (DLS) and zeta potential ( $\zeta$ ) were taken for the synthesized FeNP, as well as to the FeNP with the TEOS and APTES overlay. The results are shown in Table 1.

The DLS results were indicative that the overlay prevents the agglomeration of the nanoparticles, stabilizing the colloidal dispersion and smaller sizes of the FeNP. Moreover, the module of the zeta potential measurements shows that the particles are stabilized by electrostatic repulsion. It is also noticeable that the overlay changes imply in different zeta potentials.
Table 1. Zeta potential and DLS (average diameter) measurements of the FeNP

\begin{tabular}{|l|l|l|}
\hline Sample & DLS $(n m)$ & Zeta Potential $(\mathrm{mV})$ \\
\hline $\mathrm{Fe}_{2} \mathrm{O}_{4}$ & $642 \pm 81$ & $19.7 \pm 0.3$ \\
\hline $\mathrm{Fe}_{2} \mathrm{O}_{4}+$ TEOS & $642 \pm 21$ & $-36.4 \pm 0.7$ \\
\hline $\mathrm{Fe}_{2} \mathrm{O}_{4}+$ TEOS + APTES & $351 \pm 7$ & $26.0 \pm 1.0$ \\
\hline
\end{tabular}
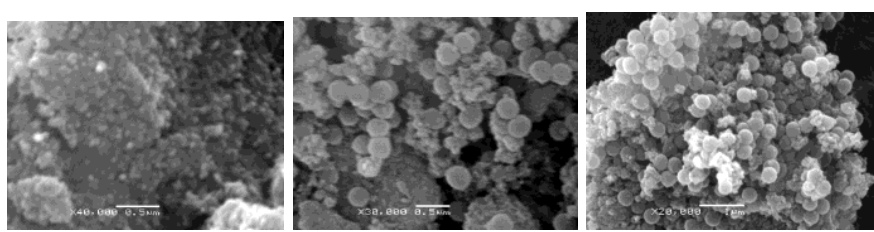

Figure 1. Scanning electron micrographs of samples of $\mathrm{Fe}_{3} \mathrm{O}_{4}$; $\mathrm{Fe}_{3} \mathrm{O}_{4}+$ TEOS and $\mathrm{Fe}_{3} \mathrm{O}_{4}+$ TEOS + APTES, respectively, from left to rigth.

The immobilization of the biological yeast invertase over the capped FeNP was also accomplished, as it was confirmed by the positive enzyme activity test results with 3,5-dinitro-2-hydroxybenzoic acid (DNS). ${ }^{6}$

\section{Conclusions}

The differences obtained in the DLS and zeta potential taken are evidences that it was possible to cap the FeNP with a TEOS and APTES overlay. Their final size was $351 \mathrm{~nm}$ with a $+26 \mathrm{mV}$ zeta potential.

The immobilization was also confirmed by the positive enzyme activity test for all the FeNPs.

\section{Acknowledgement}

We would like to express our gratitude to Professor Regina Buffon who authorized the nanoparticle synthesis in her lab under Argon atmosphere and her student Carolina Galuppo who helped in the experiments.

\footnotetext{
${ }^{1}$ Salata, O. V. J. Nanobiotechnology. 2004, 2:3

2 Mascolo, M.; Pei, Y.; Ring, T. Materials. 2013, 6:5549-5567

${ }^{3}$ Kim, D.; Zhang, Y.; Voit, W.; Rao, K.; Muhammed, M. J. Magn. Magn. Matter. 2001, 225:30-36.

4 Yamura, M.; Camilo, R.; Sampaio, L; Macêdo, M.; Nakamura, M.; Toma, H. J. Magn. Magn. Matter. 2004, 279:210-217.

5 Khatiria, R.; Reyhanic, A.; Mortazavid, S.; Hossainalipoura, M. Proceedings of the $4^{\text {th }}$ International Conference of Nanostructures (ICNS4). 2012, 14561458 .

${ }^{6}$ Miller, G. Anal Chem.. 1959, 31:426-428.
} 